(C) 2022, The Authors. Published by Elsevier Inc. and Fass Inc. on behalf of the American Dairy Science Association ${ }^{\circledR}$. This is an open access article under the CC BY license (http://creativecommons.org/licenses/by/4.0/).

\title{
Signatures of selection reveal candidate genes involved in production traits in Chinese crossbred buffaloes
}

\author{
T. X. Deng, ${ }^{1 *} \odot$ X. Y. Ma, ${ }^{1}$ X. R. Lu, ${ }^{1} \odot$ A. Q. Duan, ${ }^{1}$ Borhan Shokrollahi, ${ }^{2} \odot$ and J. H. Shang ${ }^{1 *}$ \\ ${ }^{1}$ Key Laboratory of Buffalo Genetics, Breeding and Reproduction Technology, Buffalo Research Institute, \\ Chinese Academy of Agricultural Sciences, Nanning 530001, China \\ ${ }^{2}$ Department of Animal Science, Faculty of Agriculture, Sanandaj Branch, Islamic Azad University, Sanandaj, Iran 5595-73919
}

\begin{abstract}
Identification of selection signature is important for a better understanding of genetic mechanisms that affect phenotypic differentiation in livestock. However, the genome-wide selection responses have not been investigated for the production traits of Chinese crossbred buffaloes. In this study, an SNP data set of 133 buffaloes (Chinese crossbred buffalo, $\mathrm{n}=45$; Chinese local swamp buffalo, $\mathrm{n}=88$ ) was collected from the Dryad Digital Repository database (https:/ /datadryad.org/stash/). Population genetics analysis showed that these buffaloes were divided into the following 2 groups: crossbred buffalo and swamp buffalo. The crossbred group had higher genetic diversity than the swamp group. Using 3 complementary statistical methods (integrated haplotype score, cross population extended haplotype homozygosity, and composite likelihood ratio), a total of 31 candidate selection regions were identified in the Chinese crossbred population. Here, within these candidate regions, 25 genes were under the putative selection. Among them, several candidate genes were reported to be associated with production traits. In addition, we identified 13 selection regions that overlapped with bovine QTLs that were mainly involved in milk production and composition traits. These results can provide useful insights regarding the selection response for production traits of Chinese crossbred buffalo, as identified candidate genes influence production performance.
\end{abstract}

Key words: crossbred buffalo, milk performance, signature of selection

\section{INTRODUCTION}

Buffaloes (Bubalus bubalis) are an important source of milk and meat production. Buffalo milk provides

Received August 3, 2021.

Accepted November 3, 2021.

*Corresponding authors: dtx282000@163.com and jh_shang@163 .com more than $5 \%$ of the world's milk supply (Windsor et al., 2021). Buffaloes are generally divided into 2 types, river [diploid number $(2 \mathrm{n})=50$ ] and swamp $(2 \mathrm{n}=$ 48), which differ in morphology, behavior, and the number of chromosomes (Di Berardino and Iannuzzi, 1981). River buffaloes are mainly used for milk and meat production, whereas swamp-type buffaloes are used for draft power and meat production (Zhang et al., 2020). Extensive efforts have been performed on the genetic improvement of dairy swamp buffaloes using the crossbreeding system in the southeast Asia. Over the last half-century in China, it is well known that crossbreds of the introduced river and Chinese local swamp buffalo breeds yield more milk than that of the Chinese local buffalo. Evidence shows that the river buffalo yield approximately 2,200 to $2,400 \mathrm{~kg}$ /year of milk, whereas the swamp buffalo yield only 500 to 700 $\mathrm{kg} / \mathrm{yr}$ of milk (Shi et al., 2012); the crossbred buffaloes yield an average of $\sim 1,700 \mathrm{~kg}$ of milk per lactation (Deng et al., 2019). It was reported that the milk production of Murrah crossbreds in the first and second generation respectively reached $1,240.5 \mathrm{~kg}$ and $1,423.3$ $\mathrm{kg}$, and those for Nili-Ravi crossbreds in the first and second generation respectively reached $2,041.2 \mathrm{~kg}$ and $2,351.3 \mathrm{~kg}$ as a result of a good heterosis, whereas the milk yield of the triple crossbreds and their offspring respectively reached 2,294.6 kg and 1,994.9 kg (Yang et al., 2013), as still expected by heterotic effects. Thus, the crossbred buffaloes have played an important role in meeting the Chinese rising demand for milk, making it a potential resource for the Chinese dairy market.

Today, SNP array technology is a popular and powerful tool for the assessment of genetic diversity and signature of selection in composite breeds (Kim and Rothschild, 2014; Cheruiyot et al., 2018; Singh et al., 2020). Thus far, in buffaloes, genetic improvement has been carried out by classical breeding programs and by marker-assisted selection for dairy traits such as higher concentrations of caseins (Zicarelli et al., 2020; Pauciullo et al., 2021) and milk fat (Gu et al., 2019, 2020). However, since the use of the Axiom Buffalo Genotyping Array (Iamartino et al., 2017), the information on 
genetic diversity, population structure, domestication, and migration of river- and swamp-type buffalo has also increased (Colli et al., 2018; Lu et al., 2020; Macciotta et al., 2021). This enables us to understand the resources and characteristics of buffalo breeds across the world. Moreover, identification of recent selection signatures in domesticated animals could provide genomic information of the selection response in production traits, assisting the design of more efficient selection schemes (Pan et al., 2016; Pavlidis and Alachiotis, 2017; Friedrich and Wiener, 2020). The loci and genomic regions subject to positive selection are widely reported in different domestic animals (Jahuey-Martínez et al., 2019; Manzari et al., 2019; Yu et al., 2020). There are a few reported results on the selection signature of other buffalo breeds, such as Murrah, Nili-Ravi, and crossbred breeds. Mokhber et al. (2018) identified several candidate genes associated with economically important traits in Iran Azeri and Khuzestani buffalo breeds using the buffalo SNP array. In Chinese crossbred buffalo, there is no documented information on the selective sweeps. Therefore, the current study aimed to identify selection signatures in the genome of the Chinese crossbred buffalo using 3 complementary approaches. The integrated haplotype score (iHS) was used to detect within-population selection signatures. Then, the composite likelihood ratio (CLR) test was performed to detect the selective sweep in crossbred buffalo using site frequency spectrum patterns of SNPs. Further, the crossbred buffalo were compared with swamp breeds by cross-population extended haplotype homozygosity (XP-EHH) to discover the genomic regions that correlated with the divergence of the composite from each of its parental populations since the Admixture. These identified candidate genes will help in accreting the genetic program of buffalo molecular breeding.

\section{MATERIALS AND METHODS}

\section{Ethics Statements}

Animal care and use committee approval was not required for this study because the data were obtained from an existing database.

\section{Data Source}

In this study, 2 SNP data sets of 133 buffaloes from 7 Chinese local buffalo breeds and 1 crossbred breed were collected. The 7 Chinese local buffalo breeds were Enshi $(\mathrm{n}=15)$, Fulin $(\mathrm{n}=15)$, Guizhou $(\mathrm{n}=11)$, Binhu $(\mathrm{n}=$ 15), Wenzhou $(\mathrm{n}=3)$, Haizhi $(\mathrm{n}=14)$, and Yibin $(\mathrm{n}=$
15) buffalo breeds, respectively. The Chinese crossbred buffaloes $(\mathrm{n}=45)$ were the Mediterranean $\times$ Jianghan $\times$ Nili-Ravi, Murrah $\times$ Nili-Ravi $\times$ Xilin, and Murrah $\times$ Nili-Ravi $\times$ Fuzhong buffalo breeds. Of the 133 buffaloes, 88 individuals were reported in Colli et al. (2018), and 45 animals were tested in a previous study (Deng et al., 2019). All genotyped data were generated by using the $90 \mathrm{~K}$ Affymetrix Buffalo SNP Array (Affymetrix/Thermo Fisher Scientific). The raw data were converted to the input files of PLINK v1.9 software (Purcell et al., 2007), and a data set of 63,524 SNPs was generated using the bcftools v1.12 (Danecek et al., 2021) software. Then, Beagle v5.2 software (Browning et al., 2018) was used to phase haplotypes and impute missing genotypes of the merged SNPs. The quality of imputed SNP data was controlled according to the following parameters: (1) SNP call rates >0.99; (2) individual with call rates $>0.99$; (3) SNPs with minor allele frequencies $>0.05$; $(4)$ removal of a significant $(P$ $<1 \mathrm{E}-6)$ deviation from Hardy-Weinberg equilibrium; (5) discarding of all unmapped SNPs and those on sex chromosomes. The related individuals were further removed by using the IBD method implemented in PLINK v1.9 (Purcell et al., 2007) software. In the end, a set of 35,562 SNPs from 131 buffaloes were used for the following analyses.

\section{Population Structure}

To investigate the genetic relationship between the individuals, principal component analysis (PCA) was performed using the GCTA v1.93.2 software (Yang et al., 2011). Then the first 2 principal components were plotted via the ggplot2 package in R (https://www.r -project.org/). Further, the MEGA-X software (version 10.2.6; Kumar et al., 2018) was used to construct the neighbor-joining trees of individuals to confirm the phylogenetic relationships between the breeds. Finally, the Admixture v1.30 software (Alexander and Lange, 2011) was used for the estimation of breed composition in the tested populations.

Expected heterozygosity $(\mathbf{H e})$, observed heterozygosity $(\mathbf{H o})$, effective population size $(\mathrm{Ne})$, and allelic richness $\left(\mathbf{A}_{\mathbf{R}}\right)$ were calculated to evaluate the genetic diversity of the tested buffalo populations, including the crossbred buffalo (CB; $\mathrm{n}=44$ ) and swamp buffalo $(\mathbf{S B} ; \mathrm{n}=87)$ populations. The PLINK v1.9 (Purcell et al., 2007) was used to calculate the He and Ho between alleles at 2 separate SNP loci with the default setting. The SNeP v1.1 software (Barbato et al., 2015) was used to estimate the effective population size $(\mathrm{Ne})$ in the test populations. 


\section{Signature of Selection}

Three methods, the iHS, CLR, and XP-EHH tests, were used to detect the selection signatures. First, the iHS test was used to compare the EHH between derived and ancestral alleles within the crossbred buffalo population (Voight et al., 2006). The iHS score was calculated for each autosomal SNP in the CB group using the selscan v1.3 software (Szpiech and Hernandez, 2014). The normalized iHS values were further analyzed by the norm program with the default parameters provided by selscan. The top $1 \%$ of the empirical distributions of the normalized iHS (iHS > 2.41) were considered as potential selection scans.

The CLR test uses information from allele frequencies to detect selective scans for the determination of skews in the allele spectrum to bias rare and frequent alleles (Nielsen et al., 2005). The CLR value was calculated for each autosomal SNP in the crossbred buffalo population using SweeD v4.0.0 software (Pavlidis et al., 2013). The potential selected regions were deemed as the 99.5th percentile of the empirical genome-wide distribution of CLR, as discussed by Wang et al. (2018).

Unlike within-population tests (iHS and CLR), the $\mathrm{XP}-\mathrm{EHH}$ test could detect the ongoing or approximately fixed selection signatures across the populations through comparison of the frequencies of the selected haplotypes (Sabeti et al., 2007). Here, the crossbred and the swamp buffalo populations were used as test and reference populations, respectively. The XP-EHH scores were estimated and standardized between $\mathrm{CB}$ and SB groups using selscan v1.3 software (Szpiech and Hernandez, 2014). The normalized XP-EHH values in the top $1 \%$ of the empirical distribution (XP-EHH > 2.31) are defined as the selection signatures.

Candidate selection sweep regions were detected as regions having the identified SNPs with a window size of $50 \mathrm{~kb}$ and overlapping regions with at least 2 different statistics. The selected window size was in accordance with a previous study that suggested that linkage disequilibrium in crossbred buffaloes does not exceed $50 \mathrm{~kb}$ (Deng et al., 2019). Genes within the candidate regions of the selection signatures were annotated by the gene annotation files of the buffalo genome ( $U O A_{-} W B_{-} 1$; Low et al., 2019). For the above annotated genes, the protein-coding genes were used for further analysis. The Animal Quantitative Trait Loci database (Animal QTLdb; https://data.nal.usda.gov/dataset/animal -quantitative-trait-loci-database-animal-qtldb; $\mathrm{Hu}$ et al., 2019) was used to predict the potential phenotypic traits for the candidate genes. Meanwhile, the bovine genome coordinates corresponding to the selection regions in buffalo were generated by the LiftOver (version
1.1.11; Hinrichs et al., 2006) software, which was used to identify overlapping QTL described in CattleQTLdb v. 45 (Hu et al., 2019). In addition, the published literature was used to infer the potential function of the candidate genes affecting the traits. Moreover, Gene Ontology (GO) and Kyoto Encyclopedia of Genes and Genomes (KEGG) pathway enrichment analysis for the candidate genes was performed using the KOBAS 3.0 (Bu et al., 2021) software with the Bos taurus as the background. Biological significance was considered if the number of input genes was $>2$ and $P<0.05$.

\section{RESULTS}

\section{Population Structure of Chinese Buffalo Breeds}

To investigate the breed separation among the studied populations, we analyzed the phylogenetic relationship, PCA, and population structure. The phylogenetic relationship analysis revealed that there was a distinct separation between the crossbred buffalo and swamptype buffalo (Figure 1A). In addition, the first principal component accounted for $23.74 \%$ of the total variation and separated crossbred breeds from swamp breeds (Figure 1B). The PCA further supported the results of phylogenetic analysis. A key quantity in the analysis of structured populations is the parameter $\mathrm{K}$, which describes the number of subpopulations that make up the total population. Admixture results for $\mathrm{K}=1$ to $K=4$ showed that the $K=2$ represented the most appropriate population number for the present data set (Figure 1C; Supplemental Table S1; https://doi.org/10 .7910/DVN/Z4JNVQ; Deng, 2021). These results suggested that these buffaloes can be divided into 2 groups (CB and SB) for further analysis.

The estimation of genetic diversity for the studied populations is listed in Table 1. Compared with the SB group, the CB group displayed a comparably high level of genetic diversity, as measured by He (mean $\pm \mathrm{SD}$; $0.388 \pm 0.120$ vs. $0.163 \pm 0.195)$ and Ho $(0.392 \pm 0.139$ vs. $0.162 \pm 0.196)$. In addition, the $C B$ group $\left(A_{R}=\right.$ $1.992 \pm 0.087)$ had higher $A_{R}$ values than the $S B$ group $\left(\mathrm{A}_{\mathrm{R}}=1.556 \pm 0.465\right)$. Moreover, the $N e$ values for the most recent generation (13) were 124 and 528 for $\mathrm{CB}$ and SB groups, respectively.

\section{Within-Population Selection Signatures in the Crossbred Population (iHS and CLR)}

The iHS approach was used to identify the selection sweeps based on the recent selection history in the crossbred buffalo population. The results revealed that 108 potential regions were (iHS $\geq 2.41$ ) distrib- 


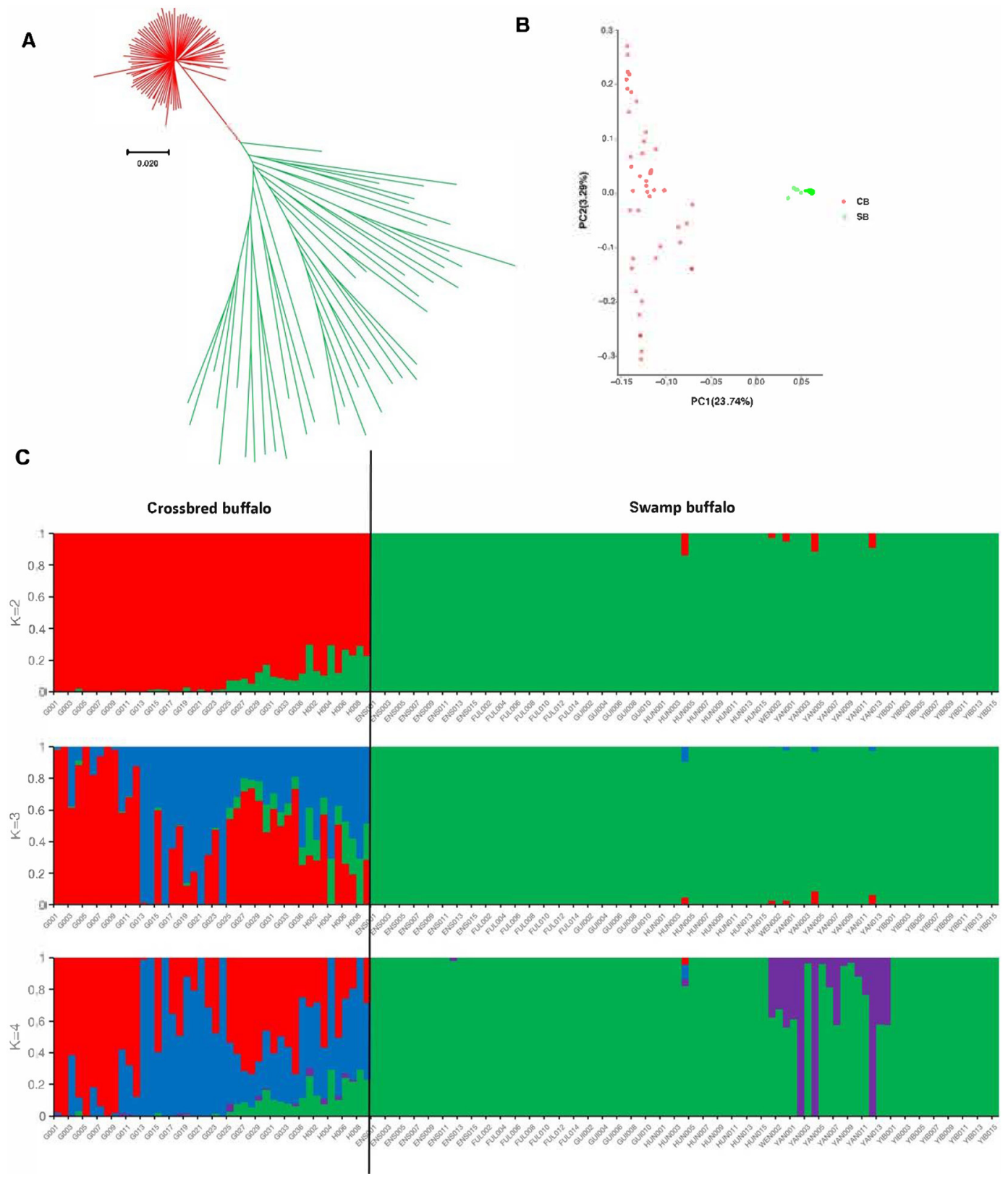

Figure 1. Phylogenetic relationship and population structure of buffalo breeds. (A) Neighbor-joining representation of the pairwise Nei's D genetic distances among populations. (B) Principal component (PC) analysis plots display the individual relationships of 131 buffaloes. (C) Population structure of 131 buffaloes inferred by model-based clustering using Admixture software. $\mathrm{K}=$ cluster number. $\mathrm{CB}=$ crossbred buffaloes; SB = swamp buffaloes.

uted across 18 autosomes of the crossbred population (Figure 2A, Supplemental Table S2; https://doi.org/10 .7910/DVN/Z4JNVQ; Deng, 2021). The strongest signal of iHS (3.7205) was found on the buffalo (Bubalus bubalis) chromosome 3 (BBU3) (163.00-163.05 Mb). The top 10 regions with their iHS values and genes are shown in Supplemental Table S3 (https://doi.org/10 .7910/DVN/Z4JNVQ; Deng, 2021). We observed that a total of 13 genes were annotated into these regions.
Alternatively, the CLR test was used to detect selective scans in the crossbred buffalo population. The findings demonstrated that 148 potential regions (CLR $\geq 4.00$ ) were distributed across 23 autosomes of the studied population (Figure 2B, Supplemental Table S4; https://doi.org/10.7910/DVN/Z4JNVQ; Deng, 2021). The strongest signature was located in the BBU2 (77.81-77.84 Mb). The top 10 regions with their CLR values and genes are represented in Supplemental Table 
Table 1. Sample description (mean $\pm \mathrm{SD}$ ) for the studied buffalo population

\begin{tabular}{lcc}
\hline Parameter $^{1}$ & Crossbred & Swamp \\
\hline $\mathrm{Nu}$ & 44 & 87 \\
$\mathrm{Ne}$ & 124 & 528 \\
$\mathrm{He}$ & $0.388 \pm 0.120$ & $0.163 \pm 0.195$ \\
$\mathrm{Ho}$ & $0.392 \pm 0.139$ & $0.162 \pm 0.196$ \\
$\mathrm{~A}_{\mathrm{R}}$ & $1.992 \pm 0.087$ & $1.556 \pm 0.465$ \\
\hline
\end{tabular}

${ }^{1} \mathrm{Nu}=$ the number of samples; $\mathrm{Ne}=$ effective population size; $\mathrm{He}=$ expected heterozygosity; $H_{0}=$ observed heterozygosity; $\mathrm{A}_{\mathrm{R}}=$ allelic richness.
S5 (https://doi.org/10.7910/DVN/Z4JNVQ; Deng, 2021). A total of 5 genes were found within these regions.

\section{Across Population Selection Signatures Based on XP-EHH}

Manhattan plots of pairwise XP-EHH analysis between $\mathrm{CB}$ and $\mathrm{SB}$ groups are presented in Figure 3. The detailed information on the 135 potential regions is displayed in Supplemental Table S6 (https://doi.org/ 10.7910/DVN/Z4JNVQ; Deng, 2021). These regions were distributed across 19 autosomes; among them, the strongest XP-EHH signal occurred at BBU3. The top

A

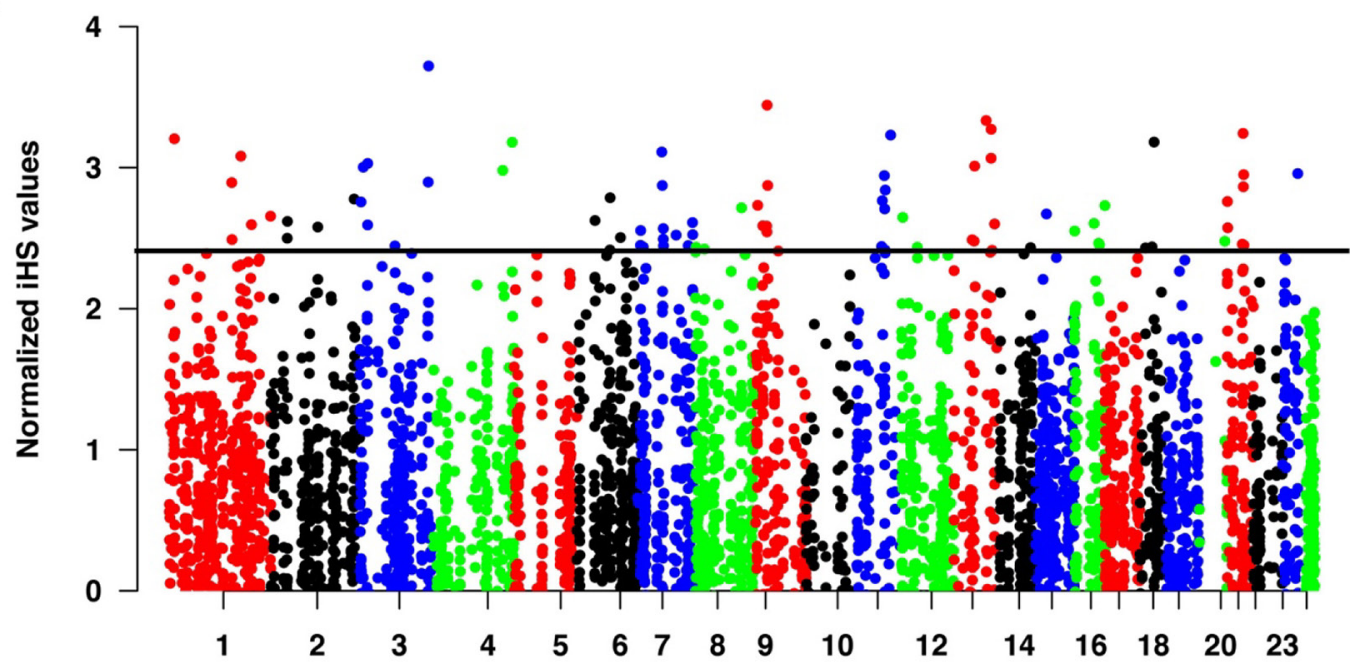

B

Chromosome

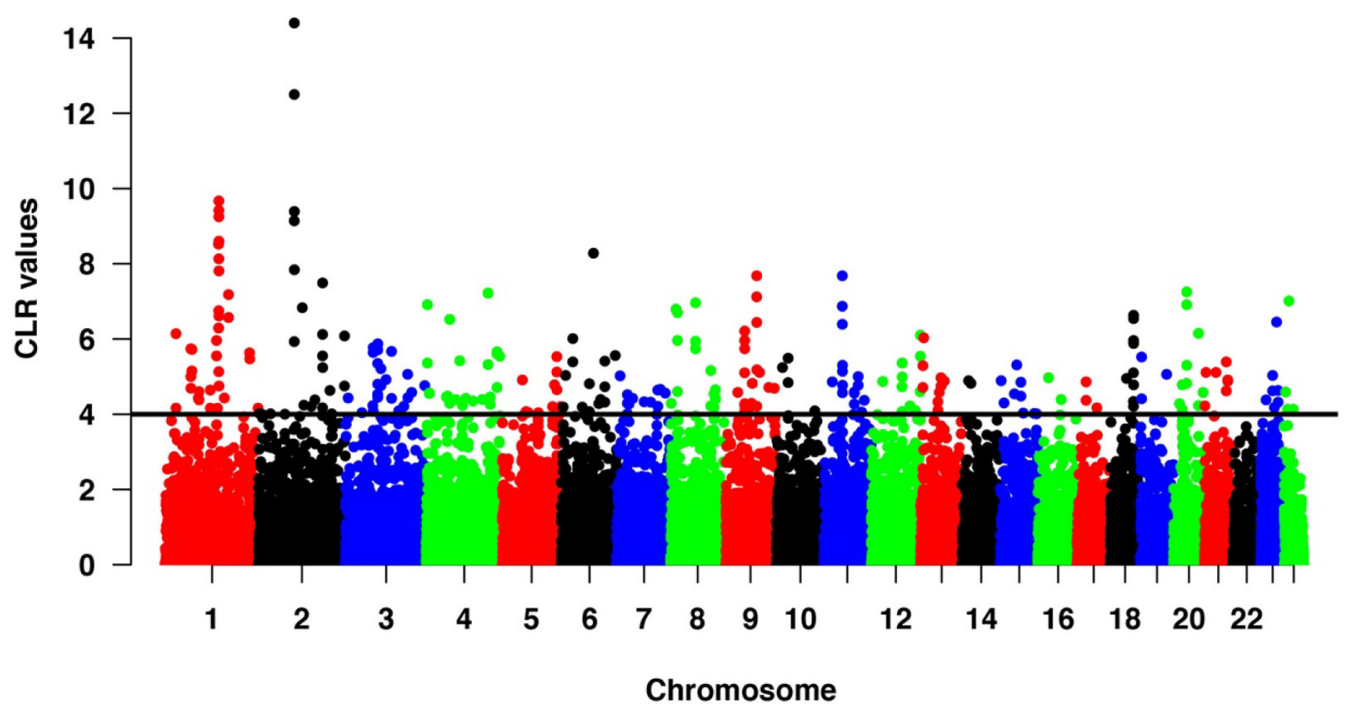

Figure 2. Manhattan plot of (A) the integrated haplotype score (iHS) and (B) composite likelihood ratio (CLR) values for the Chinese crossbred buffalo. The black line indicates the threshold level of the top $1 \%$ iHS and top $0.5 \%$ CLR values. 


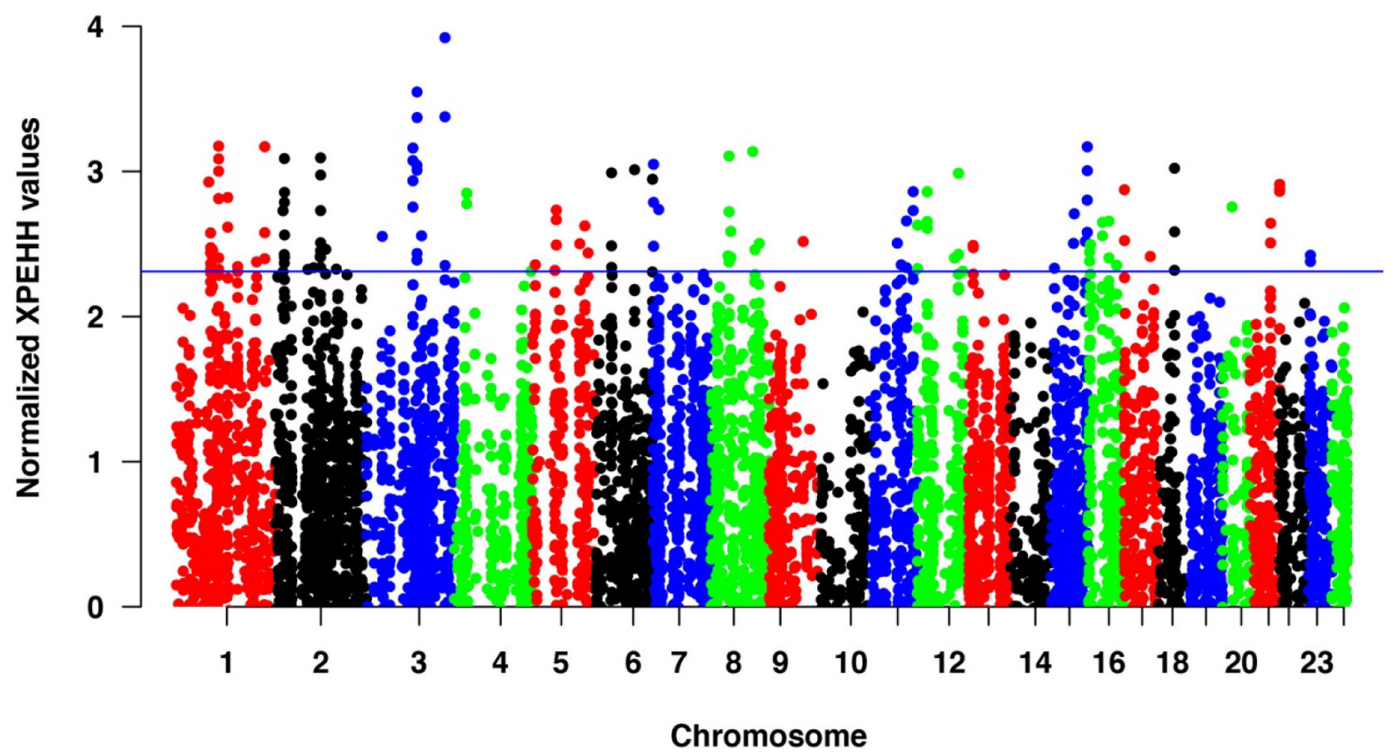

Figure 3. The cross population extended haplotype homozygosity (XP-EHH) plots for comparisons of crossbred buffaloes with swamp buffaloes. The blue line indicates the threshold level of the top $1 \% \mathrm{XP}-\mathrm{EHH}$ values.

10 regions with their XP-EHH values and genes are shown in Table 2. Results showed that 3 genes were annotated to the potential regions mentioned above.

\section{Comparative Analysis of Selective Sweep}

The distribution of overall potential selected regions detected by 3 complementary methods (iHS, CLR, and $\mathrm{XP}-\mathrm{EHH}$ ) has been shown in Figure 4. Among them, serval potential overlapping regions were observed on 11 different chromosomes, including the BBU1, BBU2, BBU3, BBU4, BBU6, BBU8, BBU9, BBU11, BBU13, $\mathrm{BBU} 15$, and BBU20. The detailed information on the overlapping regions, which were detected by at least 2 methods, is listed in Table 3 . In total, 31 regions were weighed as the final candidate regions of positive selection. A total of 25 genes were annotated into these selective sweeps. The detailed information on their GO and KEGG enrichment analyses is listed in Supplemental Table S7 (https://doi.org/10.7910/DVN/Z4JNVQ; Deng, 2021). The GO analysis showed that these genes were enriched into $10 \mathrm{GO}$ terms, including the synaptic membrane adhesion (GO:0099560), modulation of chemical synaptic transmission (GO:0050804), and PDZ domain binding (GO:0030165), among others. The KEGG enrichment analysis revealed that genes present in these regions enriched 2 pathways including the cell adhesion molecules and Axon guidance.

Further, we compared the regions under selection with the cattle QTL database, and the results are present in Supplemental Table S8 (https://doi.org/10.7910/ DVN/Z4JNVQ; Deng, 2021). We observed that a total of 61 reported QTLs were related to milk production and composition traits. Relatively concentrated areas

Table 2. List of the top 10 regions identified by cross population extended haplotype homozygosity (XP-EHH) and the genes within them

\begin{tabular}{|c|c|c|c|c|c|c|}
\hline $\mathrm{BBU}^{1}$ & $\begin{array}{l}\text { Start } \\
(\mathrm{Mb})\end{array}$ & $\begin{array}{c}\text { End } \\
(\mathrm{Mb})\end{array}$ & XP-EHH & $P$-value & Gene & Trait \\
\hline 1 & 83.80 & 83.85 & 3.1736 & 0.0011 & LOC112583749 & \\
\hline 1 & 174.43 & 174.48 & 3.1700 & 0.0011 & - & \\
\hline 3 & 155.21 & 155.26 & 3.9211 & $7.81 \mathrm{E}-05$ & - & \\
\hline 3 & 100.27 & 100.32 & 3.5467 & 0.0003 & - & \\
\hline 3 & 155.15 & 155.20 & 3.3761 & 0.0006 & - & \\
\hline 3 & 100.30 & 100.35 & 3.3707 & 0.0006 & - & \\
\hline 3 & 92.17 & 92.22 & 3.1606 & 0.0011 & FREM1 & Reproduction (Wiradjaja et al., 2013) \\
\hline 8 & 84.32 & 84.37 & 3.1362 & 0.0012 & - & \\
\hline 8 & 37.57 & 37.62 & 3.1053 & 0.0014 & $P C L O$ & Maternal calving difficulty (Purfield et al., 2015) \\
\hline 15 & 75.94 & 75.99 & 3.1692 & 0.0011 & - & \\
\hline
\end{tabular}

${ }^{1} \mathrm{BBU}=$ buffalo chromosome. 
related to milk production and composition traits were noted on BBU1, BBU6, BBU9, BBU11, and BBU13.

\section{DISCUSSION}

Chinese crossbred buffaloes are the consequence of crossbreeding program between Chinese local swamp buffaloes and river buffaloes to improve production performance over several decades ago. The performance of the resulting crossbreds significantly improved as the milk yield increased to 1,200 to $2,000 \mathrm{~kg}$ (Yang et al., 2007). Therefore, investigation of the genomic background of Chinese crossbred buffalo leads to better understanding of the major genes affecting milk production in buffaloes, which can be taken into account for future breeding programs. In the present study, a genotypic data set of 131 buffaloes (44 Chinese crossbred buffalo data included) were collected from a public database. The phylogenetic analysis results showed that animals were located into 2 groups (CB vs. SB breeds). Both PCA and Admixture analysis results further supported these results. Moreover, we observed that the CB group displayed a comparably high level of genetic diversity $[\mathrm{He}(0.388 \pm 0.120$ vs. $0.163 \pm 0.195)$ and Ho (0.392 \pm 0.139 vs. $0.162 \pm 0.196)]$ compared with the SB group. A similar result has been reported by Colli et al. (2018).

Production traits as quantitative traits are affected by many genes. Identification of causative genes or variants has a key role in uncovering the genetic architecture underlying polygenic traits in livestock such as buffaloes (Gu et al., 2019; Zicarelli et al., 2020; Pauciullo et al., 2021). Nowadays, several strategies are used to identify the causative genes or variants associated with the traits of interest, such as the candidate-gene approach (Gu et al., 2020), GWAS (Liu et al., 2018), runs of homozygosity (ROH) island (Macciotta et al., 2021), and signature of selection (Mokhber et al., 2018). In addition, the identification of causative mutations associated with the quantitative traits is still a challenge because most of these variants are located in noncoding regions of the genome. In this study, genomic regions that were under putative selection in Chinese crossbred buffaloes were investigated. According to previous studies, combined assessments of selection signatures can provide an unbiased criterion to identify variants under selection more precisely (Grossman et al., 2010; Ma et al., 2015; Ghoreishifar et al., 2020). Accordingly, 3 complementary statistical methods (iHS, CLR, and XP-EHH) were used to conduct the selective sweep analysis in the Chinese crossbred buffalo population. Using the iHS method, 81 potential regions (iHS $\geq 2.41$ ) across 18 autosomes were identified within the crossbred population (Figure 2). Focusing on the top 10

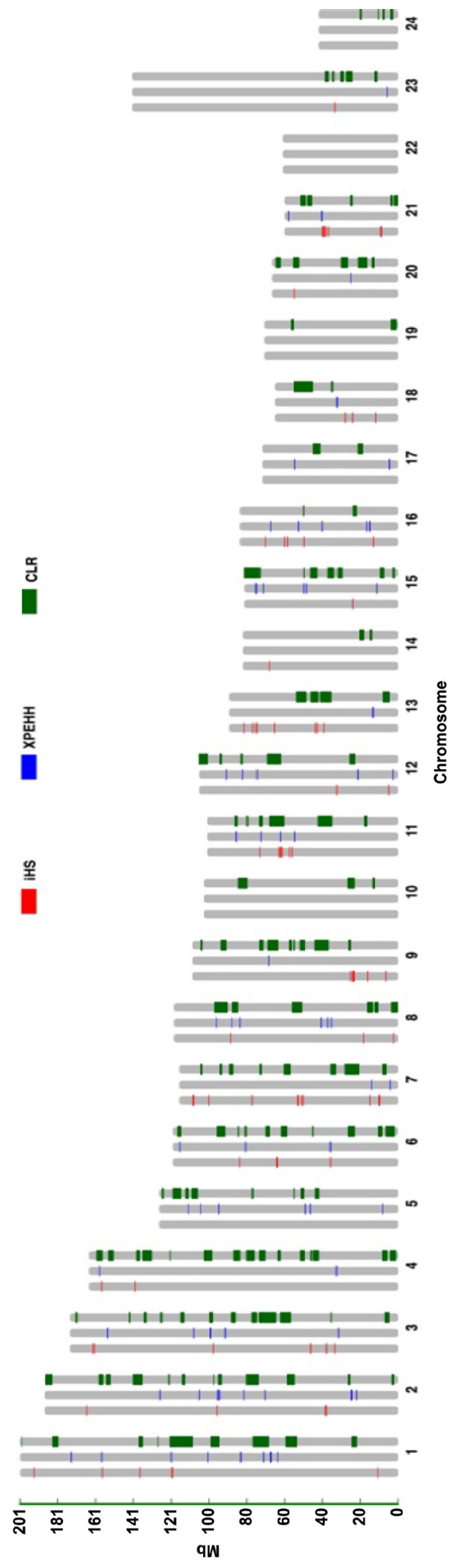

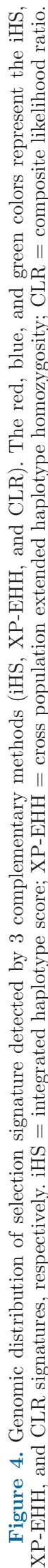


regions with the iHS values, we found 13 genes located in the potential selected regions. Among them, the LPAR1 (Ye and Chun, 2010), COX $7 C$ (Selvaraju et al., 2018), CADPS (Galliou et al., 2020), and ADAM3 (Yamaguchi et al., 2009) genes have been confirmed to be associated with reproductive traits. The CADPS gene has also been reported to be a candidate gene affecting BW (Yang et al., 2019). As for the selection signature within the population, the CLR test found 148 potential regions (CLR $\geq 4.00$ ) across 23 autosomes in the crossbred buffalo population. Notably, we observed that 5 genes were annotated into the top 10 regions with the CLR values. Among them, the NAALADL2 gene was reported to be associated with milk CLA content in cattle (Strillacci et al., 2014). By the XP-EHH method, 135 potential regions were discovered in the crossbred population. For the top 10 selected regions, we only observed the FREM1 gene annotated to the regions
(92.16 92.21 Mb) of BBU3. It has been reported to have a reproductive role (Wiradjaja et al., 2013).

By 3 methods (iHS, CLR, and XP-EHH), 31 significant signals were found in the Chinese crossbred buffalo population. Twenty-five genes (ROBO1, CCDC50, UST2B, NLGN1, ARL6IP6, NTNG1, ITGB3BP, LRRFIP1, LOC112585195, LOC112584709, EFCAB7, EXOC4, OR2T27, OR2T1, OR2T2, MDGA2, SCG5, TMCO5B, ARHGAP11A, FMN1, KIF23, PAQR5, PIBF1, KHDRBS3, and CHD2) overlapped by at least 2 methods. The ROBO1 (Nadesalingam et al., 2001) and KHDRBS3 (Jiang et al., 2019) genes were reported to be associated with milk production traits in cattle, respectively. Using the cattle QTL database, we found that 13 selection regions in crossbred buffalo population were overlapped with the bovine QTL regions (Supplemental Table S8). The corresponding regions in the bovine genome contain 61 reported QTLs

Table 3. Selection sweeps identified by at least 2 tests and annotated genes in these regions using 3 methods [cross population extended haplotype homozygosity (XP-EHH), composite likelihood ratio (CLR), and integrated haplotype score (iHS)]

\begin{tabular}{|c|c|c|c|c|c|}
\hline $\mathrm{BBU}^{1}$ & Start (bp) & End (bp) & $\begin{array}{l}\text { Detection } \\
\text { method }\end{array}$ & Gene & Trait \\
\hline 1 & $71,853,981$ & $71,935,290$ & XP-EHH, CLR & $R O B O 1^{2}$ & Milk traits (Nadesalingam et al., 2001) \\
\hline 1 & $120,339,661$ & $120,389,661$ & iHS, CLR & - & - \\
\hline 1 & $121,102,139$ & $121,193,883$ & XP-EHH, CLR & LOC112585195 & - \\
\hline 1 & $137,786,832$ & $137,836,832$ & iHS, CLR & $N L G N 1^{2}$ & Growth traits (Zhuang et al., 2020) \\
\hline 2 & $95,054,201$ & $95,104,201$ & XP-EHH, CLR & - & - \\
\hline 4 & $158,354,717$ & $158,404,717$ & iHS, CLR & LOC112584709 & - \\
\hline 4 & $159,553,844$ & $159,603,844$ & XP-EHH, CLR & - & - \\
\hline 6 & $36,001,246$ & $36,051,246$ & iHS, XP-EHH & $N T N G 1^{2}$ & $\begin{array}{l}\text { Inseminations per conception (Galliou et al., } \\
\text { 2020); BW (Cole et al., 2014) }\end{array}$ \\
\hline 6 & $81,364,748$ & $81,414,748$ & XP-EHH, CLR & ITGBЗBP, EFCABך & - \\
\hline 6 & $116,680,610$ & $116,730,610$ & XP-EHH, CLR & $L R R F I P 1^{2}$ & Fat deposition (Stambuk et al., 2020) \\
\hline 11 & $61,891,319$ & $61,941,319$ & iHS, CLR & - & - \\
\hline 11 & $62,608,836$ & $62,934,032$ & $\begin{array}{l}\text { XP-EHH, CLR, } \\
\text { iHS }\end{array}$ & $M D G A 2$ & - \\
\hline 11 & $63,715,423$ & $63,765,423$ & iHS, CLR & - & - \\
\hline 11 & $73,239,962$ & $73,289,962$ & XP-EHH, CLR & - & - \\
\hline 11 & $73,288,129$ & $73,338,129$ & XP-EHH, CLR & ARHGAP11A, SCG5 & - \\
\hline 11 & $73,987,833$ & $74,037,833$ & iHS, CLR & $F M N 1,{ }^{2} T M C O 5 B$ & $\begin{array}{l}\text { Age at second calving (Buzanskas et al., } \\
\text { 2017) }\end{array}$ \\
\hline 11 & $86,353,809$ & $86,512,307$ & XP-EHH, CLR & KIF23, PAQR5 & - \\
\hline 13 & $39,474,821$ & $39,524,821$ & iHS, CLR & - & - \\
\hline 13 & $43,132,835$ & $43,182,835$ & iHS, CLR & $P I B F 1^{2}$ & Embryonic development (Tao et al., 2021) \\
\hline 13 & $44,092,925$ & $44,142,925$ & iHS, CLR & - & - \\
\hline 15 & $75,778,026$ & $75,888,166$ & XP-EHH, CLR & KHDRBS $3^{2}$ & Milk traits (Rutten et al., 2013) \\
\hline 15 & $75,939,189$ & $760,162,96$ & XP-EHH, CLR & & - \\
\hline
\end{tabular}

${ }^{1} \mathrm{BBU}=$ buffalo chromosome.

${ }^{2}$ Genes found in the literature to be associated with specific traits related to livestock breeding. 
that are related to the milk production and composition traits. Relatively concentrated areas related to milk production and composition traits were noted on BBU1, BBU6, BBU9, BBU11, and BBU13. The results suggested that these candidate genes (including the ROBO1, LRRFIP1, ARHGAP11A, SCG, FMN1, $T M C O 5 B, P I B F 1$, and KHDRBS3) within the regions might play vital roles in milk production traits in buffaloes. Moreover, 4 genes were reported to be associated with reproduction traits in different farm animals, such as the NTNG1 gene with inseminations per conception in cattle (Galliou et al., 2020), the FMN1 gene with age at second calving in cattle (Buzanskas et al., 2017), the PIBF1 gene with embryonic development in sheep (Tao et al., 2021), and the CHD2 gene with sperm quality in pig (Gòdia et al., 2020). In addition, Cole et al. (2014) also found that $N L G N 1$ was the candidate gene influencing the BW in pigs. Moreover, our findings showed that 3 genes (OR2T27, OR2T1, OR2T2) belonged to members of the olfactory receptor gene family (Olender et al., 2008). The olfactory receptors have vital roles in the regulation of appetite in humans and rodents, which can affect animal production efficiency (Connor et al., 2018). Therefore, the 3 olfactory receptor genes could have some function in the production performance in buffaloa.

\section{CONCLUSIONS}

In the present study, we investigated the population structure and genetic diversity of Chinese crossbred buffalo. Using 3 complementary statistical methods, 31 candidate selection regions were detected in the Chinese crossbred population. Among them, several candidate genes were reported to be associated with production traits and adaptation. In addition, we identified 13 selection regions that overlapped with bovine QTLs that were mainly involved in milk production and composition traits. These results provided useful insights into the selection responses for production traits in Chinese crossbred buffalo and identified serval candidate genes influencing production performance.

\section{ACKNOWLEDGMENTS}

This study was funded by the China National Key R\&D Program (2017YFE0113800) of the Ministry of Science and Technology of China (Beijing, China), and the Key Research and Development Program in Guangxi (Guike AB1850013) and the Natural Science Foundation of Guangxi (2020GXNSFDA297032) of the Department of Science and Technology of Guangxi Zhuang Autonomous Region (Nanning, China). The authors have not stated any conflicts of interest.

\section{REFERENCES}

Alexander, D. H., and K. Lange. 2011. Enhancements to the ADMIXTURE algorithm for individual ancestry estimation. BMC Bioinformatics 12:246. https://doi.org/10.1186/1471-2105-12-246.

Barbato, M., P. Orozco-terWengel, M. Tapio, and M. W. Bruford. 2015. SNeP: A tool to estimate trends in recent effective population size trajectories using genome-wide SNP data. Front. Genet. 6:109. https://doi.org/10.3389/fgene.2015.00109.

Browning, B. L., Y. Zhou, and S. R. Browning. 2018. A one-penny imputed genome from next-generation reference panels. Am. J. Hum. Genet. 103:338-348. https://doi.org/10.1016/j.ajhg.2018.07.015.

Bu, D., L. H. Luo, P. Huo, Z. Wang, S. Zhang, Z. He, Y. Wu, L. Zhao, J. Liu, J. Guo, S. Fang, W. Cao, L. Yi, Y. Zhao, and L. Kong. 2021. KOBAS-i: Intelligent prioritization and exploratory visualization of biological functions for gene enrichment analysis. Nucleic Acids Res. 49:W317-W325. https://doi.org/10.1093/nar/gkab447.

Buzanskas, M. E., D. D. A. Grossi, R. V. Ventura, F. S. Schenkel, T. C. S. Chud, N. B. Stafuzza, L. D. Rola, S. L. C. Meirelles, F. B. Mokry, M. A. Mudadu, R. H. Higa, M. da Silva, M. M. de Alencar, L. C. A. Regitano, and D. P. Munari. 2017. Candidate genes for male and female reproductive traits in Canchim beef cattle. J. Anim. Sci. Biotechnol. 8:67. https://doi.org/10.1186/s40104-017 $-0199-8$.

Cheruiyot, E. K., R. C. Bett, J. O. Amimo, Y. Zhang, R. Mrode, and F. D. N. Mujibi. 2018. Signatures of selection in admixed dairy cattle in Tanzania. Front. Genet. 9:607. https://doi.org/10.3389/ fgene.2018.00607.

Cole, J. B., B. Waurich, M. Wensch-Dorendorf, D. M. Bickhart, and H. H. Swalve. 2014. A genome-wide association study of calf birth weight in Holstein cattle using single nucleotide polymorphisms and phenotypes predicted from auxiliary traits. J. Dairy Sci. 97:3156-3172. https://doi.org/10.3168/jds.2013-7409.

Colli, L., M. Milanesi, E. Vajana, D. Iamartino, L. Bomba, F. Puglisi, M. Del Corvo, E. L. Nicolazzi, S. S. E. Ahmed, J. R. V. Herrera, L. Cruz, S. Zhang, A. Liang, G. Hua, L. Yang, X. Hao, F. Zuo, S. J. Lai, S. Wang, R. Liu, Y. Gong, M. Mokhber, Y. Mao, F. Guan, A. Vlaic, B. Vlaic, L. Ramunno, G. Cosenza, A. Ahmad, I. Soysal, E. Ünal, M. Ketudat-Cairns, J. F. Garcia, Y. T. Utsunomiya, P. S. Baruselli, M. E. J. Amaral, R. Parnpai, M. G. Drummond, P. Galbusera, J. Burton, E. Hoal, Y. Yusnizar, C. Sumantri, B. Moioli, A. Valentini, A. Stella, J. L. Williams, and P. Ajmone-Marsan. 2018. New insights on water buffalo genomic diversity and post-domestication migration routes from medium density SNP chip data. Front. Genet. 9:53. https://doi.org/10.3389/fgene.2018.00053.

Connor, E. E., Y. Zhou, and G. E. Liu. 2018. The essence of appetite: Does olfactory receptor variation play a role? J. Anim. Sci. 96:1551-1558. https://doi.org/10.1093/jas/sky068.

Danecek, P., J. K. Bonfield, J. Liddle, J. Marshall, V. Ohan, M. O. Pollard, A. Whitwham, T. Keane, S. A. McCarthy, R. M. Davies, and H. Li. 2021. Twelve years of SAMtools and BCFtools. Gigascience 10:giab008.

Deng, T. 2021. Signatures of selection reveal candidate genes involved in production traits in Chinese crossbred buffaloes. V1. Harvard Dataverse. https://doi.org/10.7910/DVN/Z4JNVQ.

Deng, T., A. Liang, J. Liu, G. Hua, T. Ye, S. Liu, G. Campanile, G. Plastow, C. Zhang, Z. Wang, A. Salzano, B. Gasparrini, M. Cassandro, H. Riaz, X. Liang, and L. Yang. 2019. Genome-wide SNP data revealed the extent of linkage disequilibrium, persistence of phase and effective population size in purebred and crossbred buffalo populations. Front. Genet. 9:688. https://doi.org/10.3389/ fgene.2018.00688.

Di Berardino, D., and L. Iannuzzi. 1981. Chromosome banding homologies in Swamp and Murrah buffalo. J. Hered. 72:183-188. https:/ /doi.org/10.1093/oxfordjournals.jhered.a109469.

Friedrich, J., and P. Wiener. 2020. Selection signatures for high-altitude adaptation in ruminants. Anim. Genet. 51:157-165. https:// doi.org/10.1111/age.12900.

Galliou, J. M., J. N. Kiser, K. F. Oliver, C. M. Seabury, J. G. N. Moraes, G. W. Burns, T. E. Spencer, J. Dalton, and H. L. Neibergs. 2020. Identification of loci and pathways associated with 
heifer conception rate in U.S. Holsteins. Genes (Basel) 11:767. https://doi.org/10.3390/genes11070767.

Ghoreishifar, S. M., S. Eriksson, A. M. Johansson, M. Khansefid, S. Moghaddaszadeh-Ahrabi, N. Parna, P. Davoudi, and A. Javanmard. 2020. Signatures of selection reveal candidate genes involved in economic traits and cold acclimation in five Swedish cattle breeds. Genet. Sel. Evol. 52:52. https://doi.org/10.1186/s12711 -020-00571-5.

Gòdia, M., A. Reverter, R. González-Prendes, Y. Ramayo-Caldas, A. Castelló, J.-E. Rodríguez-Gil, A. Sánchez, and A. Clop. 2020. A systems biology framework integrating GWAS and RNA-seq to shed light on the molecular basis of sperm quality in swine. Genet. Sel. Evol. 52:72. https://doi.org/10.1186/s12711-020-00592-0.

Grossman, S. R., I. Shylakhter, E. K. Karlsson, E. H. Byrne, S. Morales, G. Frieden, E. Hostetter, E. Angelino, M. Garber, O. Zuk, E. S. Lander, S. F. Schaffner, and P. C. Sabeti. 2010. A composite of multiple signals distinguishes causal variants in regions of positive selection. Science 327:883-886. https://doi.org/10.1126/ science.1183863.

Gu, M., G. Cosenza, G. Gaspa, M. Iannaccone, N. P. P. Macciotta, G. Chemello, L. Di Stasio, and A. Pauciullo. 2020. Sequencing of lipoprotein lipase gene in the Mediterranean river buffalo identified novel variants affecting gene expression. J. Dairy Sci. 103:63746382. https://doi.org/10.3168/jds.2019-17968.

Gu, M., G. Cosenza, M. Iannaccone, N. P. P. Macciotta, Y. Guo, L. Di Stasio, and A. Pauciullo. 2019. The single nucleotide polymorphism g.133A $>$ C in the stearoyl CoA desaturase gene (SCD) promoter affects gene expression and quali-quantitative properties of river buffalo milk. J. Dairy Sci. 102:442-451. https://doi.org/10 $.3168 /$ jds.2018-15059

Hinrichs, A. S., D. Karolchik, R. Baertsch, G. P. Barber, G. Bejerano, H. Clawson, M. Diekhans, T. S. Furey, R. A. Harte, F. Hsu, J. Hillman-Jackson, R. M. Kuhn, J. S. Pedersen, A. Pohl, B. J. Raney, K. R. Rosenbloom, A. Siepel, K. E. Smith, C. W. Sugnet, A. Sultan-Qurraie, D. J. Thomas, H. Trumbower, R. J. Weber, M. Weirauch, A. S. Zweig, D. Haussler, and W. J. Kent. 2006. The UCSC Genome Browser Database: Update 2006. Nucleic Acids Res. 34:D590-D598. https://doi.org/10.1093/nar/gkj144.

Hu, Z.-L., C. A. Park, and J. M. Reecy. 2019. Building a livestock genetic and genomic information knowledgebase through integrative developments of Animal QTLdb and CorrDB. Nucleic Acids Res. 47(D1):D701-D710. https://doi.org/10.1093/nar/gky1084.

Iamartino, D., E. L. Nicolazzi, C. P. Van Tassell, J. M. Reecy, E. R. Fritz-Waters, J. E. Koltes, S. Biffani, T. S. Sonstegard, S. G. Schroeder, P. Ajmone-Marsan, R. Negrini, R. Pasquariello, P. Ramelli, A. Coletta, J. F. Garcia, A. Ali, L. Ramunno, G. Cosenza, D. A. A. de Oliveira, M. G. Drummond, E. Bastianetto, A. Davassi, A. Pirani, F. Brew, and J. L. Williams. 2017. Design and validation of a 90K SNP genotyping assay for the water buffalo (Bubalus bubalis). PLoS One 12:e0185220. https://doi.org/10.1371/journal .pone.0185220.

Jahuey-Martínez, F. J., G. M. Parra-Bracamonte, A. M. SifuentesRincón, and V. R. Moreno-Medina. 2019. Signatures of selection in Charolais beef cattle identified by genome-wide analysis. J. Anim. Breed. Genet. 136:378-389. https://doi.org/10.1111/jbg.12399.

Jiang, J., L. Ma, D. Prakapenka, P. M. VanRaden, J. B. Cole, and Y. Da. 2019. A large-scale genome-wide association study in U.S. Holstein cattle. Front. Genet. 10:412. https://doi.org/10.3389/fgene 2019.00412

Kim, E. S., and M. F. Rothschild. 2014. Genomic adaptation of admixed dairy cattle in East Africa. Front. Genet. 5:443. https://doi .org/10.3389/fgene.2014.00443.

Kumar, S., G. Stecher, M. Li, C. Knyaz, and K. Tamura. 2018. MEGA $\mathrm{X}$ : Molecular evolutionary genetics analysis across computing platforms. Mol. Biol. Evol. 35:1547-1549. https://doi.org/10.1093/ molbev/msy096.

Liu, J. J., A. X. Liang, G. Campanile, G. Plastow, C. Zhang, Z. Wang, A. Salzano, B. Gasparrini, M. Cassandro, and L. G. Yang. 2018. Genome-wide association studies to identify quantitative trait loci affecting milk production traits in water buffalo. J. Dairy Sci. 101:433-444. https://doi.org/10.3168/jds.2017-13246.
Low, W. Y., R. Tearle, D. M. Bickhart, B. D. Rosen, S. B. Kingan, T. Swale, F. Thibaud-Nissen, T. D. Murphy, R. Young, L. Lefevre, D. A. Hume, A. Collins, P. Ajmone-Marsan, T. P. L. Smith, and J. L. Williams. 2019. Chromosome-level assembly of the water buffalo genome surpasses human and goat genomes in sequence contiguity. Nat. Commun. 10:260. https://doi.org/10.1038/s41467 -018-08260-0.

Lu, X. R., A. Q. Duan, W. Q. Li, H. Abdel-Shafy, H. E. Rushdi, S. S. Liang, X. Y. Ma, X. W. Liang, and T. X. Deng. 2020. Genomewide analysis reveals genetic diversity, linkage disequilibrium, and selection for milk production traits in Chinese buffalo breeds. J. Dairy Sci. 103:4545-4556. https://doi.org/10.3168/jds.2019-17364.

Ma, Y., X. Ding, S. Qanbari, S. Weigend, Q. Zhang, and H. Simianer. 2015. Properties of different selection signature statistics and a new strategy for combining them. Heredity 115:426-436. https:// doi.org/10.1038/hdy.2015.42.

Macciotta, N. P. P., L. Colli, A. Cesarani, P. Ajmone-Marsan, W. Y. Low, R. Tearle, and J. L. Williams. 2021. The distribution of runs of homozygosity in the genome of river and swamp buffaloes reveals a history of adaptation, migration and crossbred events. Genet. Sel. Evol. 53:20. https://doi.org/10.1186/s12711-021-00616-3.

Manzari, Z., H. Mehrabani-Yeganeh, A. Nejati-Javaremi, M. H. Moradi, and M. Gholizadeh. 2019. Detecting selection signatures in three Iranian sheep breeds. Anim. Genet. 50:298-302. https://doi .org/10.1111/age.12772.

Mokhber, M., M. Moradi-Shahrbabak, M. Sadeghi, H. Moradi-Shahrbabak, A. Stella, E. Nicolzzi, J. Rahmaninia, and J. L. Williams. 2018. A genome-wide scan for signatures of selection in Azeri and Khuzestani buffalo breeds. BMC Genomics 19:449. https://doi .org/10.1186/s12864-018-4759-x.

Nadesalingam, J., Y. Plante, and J. P. Gibson. 2001. Detection of QTL for milk production on chromosomes 1 and 6 of Holstein cattle. Mamm. Genome 12:27-31. https://doi.org/10.1007/ s003350010232.

Nielsen, R., S. Williamson, Y. Kim, M. J. Hubisz, A. G. Clark, and C. Bustamante. 2005. Genomic scans for selective sweeps using SNP data. Genome Res. 15:1566-1575. https://doi.org/10.1101/ gr.4252305.

Olender, T., D. Lancet, and D. W. Nebert. 2008. Update on the olfactory receptor (OR) gene superfamily. Hum. Genomics 3:87. https: //doi.org/10.1186/1479-7364-3-1-87.

Pan, Z. Y., X. Y. He, X. Y. Wang, X. F. Guo, X. Cao, W. P. Hu, R. Di, Q. Y. Liu, and M. X. Chu. 2016. Selection signature in domesticated animals. Yi Chuan 38:1069-1080.

Pauciullo, A., S. Martorello, K. Carku, C. Versace, A. Coletta, and G. Cosenza. 2021. A novel duplex ACRS-PCR for composite CSN1S1-CSN3 genotype discrimination in domestic buffalo. Ital. J. Anim. Sci. 20:1264-1269. https://doi.org/10.1080/1828051X .2021 .1952912 .

Pavlidis, P., and N. Alachiotis. 2017. A survey of methods and tools to detect recent and strong positive selection. J. Biol. Res. (Thessalon.) 24:7. https://doi.org/10.1186/s40709-017-0064-0.

Pavlidis, P., D. Živković, A. Stamatakis, and N. Alachiotis. 2013. SweeD: Likelihood-based detection of selective sweeps in thousands of genomes. Mol. Biol. Evol. 30:2224-2234. https://doi.org/ $10.1093 / \mathrm{molbev} / \mathrm{mst112}$

Purcell, S., B. Neale, K. Todd-Brown, L. Thomas, M. A. R. Ferreira, D. Bender, J. Maller, P. Sklar, P. I. W. de Bakker, M. J. Daly, and P. C. Sham. 2007. PLINK: a tool set for whole-genome association and population-based linkage analyses. Am. J. Hum. Genet. 81:559-575. https://doi.org/10.1086/519795.

Purfield, D. C., D. G. Bradley, R. D. Evans, F. J. Kearney, and D. P. Berry. 2015. Genome-wide association study for calving performance using high-density genotypes in dairy and beef cattle. Genet. Sel. Evol. 47:47. https://doi.org/10.1186/s12711-015-0126-4.

Rutten, M. J., A. C. Bouwman, R. C. Sprong, J. A. van Arendonk, and M. H. Visker. 2013. Genetic variation in vitamin B-12 content of bovine milk and its association with SNP along the bovine genome. PLoS One 8:e62382. https://doi.org/10.1371/journal.pone .0062382 . 
Sabeti, P. C., P. Varilly, B. Fry, J. Lohmueller, E. Hostetter, and C. Cotsapas.. 2007. Genome-wide detection and characterization of positive selection in human populations. Nature 449:913-918. https://doi.org/10.1038/nature06250.

Selvaraju, S., S. Parthipan, L. Somashekar, B. K. Binsila, A. P. Kolte, A. Arangasamy, J. P. Ravindra, and S. A. Krawetz. 2018. Current status of sperm functional genomics and its diagnostic potential of fertility in bovine (Bos taurus). Syst Biol Reprod Med 64:484-501. https://doi.org/10.1080/19396368.2018.1444816.

Shi, D. S., J. Wang, Y. Yang, F. H. Lu, X. P. Li, and Q. Y. Liu. 2012. DGAT1, GH, GHR, PRL and PRLR polymorphism in water buffalo (Bubalus bubalis). Reprod. Domest. Anim. 47:328-334. https:/ /doi.org/10.1111/j.1439-0531.2011.01876.x.

Singh, A., A. Mehrotra, C. Gondro, A. Romero, A. K. Pandey, A. Karthikeyan, A. Bashir, B. P. Mishra, T. Dutt, and A. Kumar. 2020. Signatures of selection in composite Vrindavani cattle of India. Front. Genet. 11:589496. https://doi.org/10.3389/fgene.2020 .589496 .

Stambuk, C. R., E. A. Staiger, B. J. Heins, and H. J. Huson. 2020. Exploring physiological and genetic variation of digital cushion thickness in Holstein and Jersey cows and bulls. J. Dairy Sci. 103:9177-9194. https://doi.org/10.3168/jds.2020-18290.

Strillacci, M. G., E. Frigo, F. Canavesi, Y. Ungar, F. Schiavini, L. Zaniboni, L. Reghenzani, M. C. Cozzi, A. B. Samoré, Y. Kashi, E. Shimoni, R. Tal-Stein, M. Soller, E. Lipkin, and A. Bagnato. 2014. Quantitative trait loci mapping for conjugated linoleic acid, vaccenic acid and $\Delta(9)$-desaturase in Italian Brown Swiss dairy cattle using selective DNA pooling. Anim. Genet. 45:485-499. https:// doi.org/10.1111/age.12174.

Szpiech, Z. A., and R. D. Hernandez. 2014. Selscan: An efficient multithreaded program to perform EHH-based scans for positive selection. Mol. Biol. Evol. 31:2824-2827. https://doi.org/10.1093/ molbev/msu211.

Tao, L., X. Y. He, F. Y. Wang, L. X. Pan, X. Y. Wang, S. Q. Gan, R. Di, and M. X. Chu. 2021. Identification of genes associated with litter size combining genomic approaches in Luzhong mutton sheep. Anim. Genet. 52:545-549. https://doi.org/10.1111/age .13078 .

Voight, B. F., S. Kudaravalli, X. Wen, and J. K. Pritchard. 2006. A map of recent positive selection in the human genome. PLoS Biol. 4:e72. https://doi.org/10.1371/journal.pbio.0040072.

Wang, K., P. Wu, Q. Yang, D. Chen, J. Zhou, A. Jiang, J. Ma, Q. Tang, W. Xiao, Y. Jiang, L. Zhu, X. Li, and G. Tang. 2018. Detection of selection signatures in Chinese Landrace and Yorkshire pigs based on genotyping-by-sequencing data. Front. Genet. 9:119. https://doi.org/10.3389/fgene.2018.00119.

Windsor, P., S. Martin, S. Khounsy, J. Young, P. Thomson, and R. Bush. 2021. Improved milk production from supplementation of Swamp Buffalo with molasses nutrient blocks containing $10 \%$ urea. Dairy 2:90-103. https://doi.org/10.3390/dairy2010009.
Wiradjaja, F., D. L. Cottle, L. Jones, and I. Smyth. 2013. Regulation of PDGFC signalling and extracellular matrix composition by FREM1 in mice. Dis. Model. Mech. 6:1426-1433. https://doi.org/ 10.1242/dmm.013748.

Yamaguchi, R., Y. Muro, A. Isotani, K. Tokuhiro, K. Takumi, I. Adham, M. Ikawa, and M. Okabe. 2009. Disruption of ADAM3 impairs the migration of sperm into oviduct in mouse. Biol. Reprod. 81:142-146. https://doi.org/10.1095/biolreprod.108.074021.

Yang, B., X. Liang, J. Qin, C. Yang, and J. Shagn. 2013. Brief Introduction to the Development of Chinese Dairy Buffalo Industry. Pages 111-120 in 10th World Buffalo Congress and 7th Asian Buffalo Congress. International Buffalo Information Center.

Yang, B., X. Liang, Q. Zeng, J. Qin, and C. Yang. 2007. Dairy buffalo breeding in countryside of China. Ital. J. Anim. Sci. 6(sup2):25-29. https://doi.org/10.4081/ijas.2007.s2.25.

Yang, J., S. H. Lee, M. E. Goddard, and P. M. Visscher. 2011. GCTA: A tool for genome-wide complex trait analysis. Am. J. Hum. Genet. 88:76-82. https://doi.org/10.1016/j.ajhg.2010.11.011.

Yang, Q., P. Wu, K. Wang, D. Chen, J. Zhou, J. Ma, M. Li, W. Xiao, A. Jiang, Y. Jiang, L. Bai, L. Zhu, X. Li, and G. Tang. 2019 SNPs associated with body weight and backfat thickness in two pig breeds identified by a genome-wide association study. Genomics 111:1583-1589. https://doi.org/10.1016/j.ygeno.2018.11.002.

Ye, X., and J. Chun. 2010. Lysophosphatidic acid (LPA) signaling in vertebrate reproduction. Trends Endocrinol. Metab. 21:17-24. https://doi.org/10.1016/j.tem.2009.08.003.

Yu, J., P. Zhao, X. Zheng, L. Zhou, C. Wang, and J. F. Liu. 2020. Genome-wide detection of selection signatures in Duroc revealed candidate genes relating to growth and meat quality. G3 (Bethesda) 10:3765-3773. https://doi.org/10.1534/g3.120.401628.

Zhang, Y., L. Colli, and J. S. F. Barker. 2020. Asian water buffalo: Domestication, history and genetics. Anim. Genet. 51:177-191. https: //doi.org/10.1111/age.12911.

Zhuang, Z., L. Xu, J. Yang, H. Gao, L. Zhang, X. Gao, J. Li, and B. Zhu. 2020. Weighted single-step genome-wide association study for growth traits in Chinese Simmental beef cattle. Genes (Basel) 11:189. https://doi.org/10.3390/genes11020189.

Zicarelli, L., R. Di Palo, R. Napolano, H. Tonhati, E. De Carlo, R. Gagliardi, A. Di Luccia, and B. la Gatta. 2020. Influence of $\alpha$ S1casein and $\kappa$-casein polymorphism on the curd yield of Italian Mediterranean buffalo (Bubalus bubalis L.) milk. Int. Dairy J. 100:104559. https://doi.org/10.1016/j.idairyj.2019.104559.

\section{ORCIDS}

T. X. Deng ๑ https://orcid.org/0000-0002-7442-6739

X. R. Lu ๑ https://orcid.org/0000-0002-7822-6953

Borhan Shokrollahi ৫ https://orcid.org/0000-0001-7938-5051 